\title{
Influence evaluation of the ship propulsion system on the energy efficiency for small, medium and large container vessels
}

Viktor Nikiforov ${ }^{1, *}$, Irina Kostova ${ }^{1}$

${ }^{1}$ Technical University of Varna, Department of Naval Architecture and Marine Engineering, 9000 Varna, Bulgaria

\begin{abstract}
The transportation of goods worldwide has a vital meaning for the entire of humanity. The seaborne transport is considered to be the most efficient - economically and environmentally friendly way to convey large amount of goods when compared to the other transport options available. Marine vessels contribute for the carriage of about 90 percent of the worldwide trade and a significant part of the goods delivered by sea are performed by container vessels. Even considered as the most efficient way of transportation the negative aspects of the shipping should not be neglected. The fuels intended for the ship propulsion generating enormous amounts of Greenhouse gases (GHG) and harmful emissions which are directly released into the atmosphere. When it comes to Energy Efficiency of the ships, the proper selection of the propulsion system and the fuel type used are essential with regard to achieve the best values. In the current paper a diverse alternative propulsion system options in order to achieve maximum Energy Efficiency on various sizes of container vessels will be analyzed.
\end{abstract}

\section{Introduction}

The basic goal set in front of the today's worldwide shipping is to reduce the negative effect caused by the generation of the GHG and harmful gases produced when ship's operation. The goods transportation via ships is considered for about 90 percent of the global trade and the main ships type involved in it is the container class.

In terms of value, global seaborne container trade is believed to account for approximately 60 percent of all world seaborne trade, which was valued at around 12 trillion U.S. dollars in 2017 [1].

The GHG emissions - including carbon dioxide $\left(\mathrm{CO}_{2}\right)$, methane $\left(\mathrm{CH}_{4}\right)$ and nitrous oxide $\left(\mathrm{N}_{2} \mathrm{O}\right)$, expressed in $\mathrm{CO}_{2} \mathrm{e}$ - of total shipping have increased from 977 million tonnes in 2012 to 1,076 million tonnes in 2018 (9.6\% increase). In 2012, 962 million tonnes were $\mathrm{CO}_{2}$ emissions, while in 2018 this amount grew $9.3 \%$ to 1,056 million tonnes of $\mathrm{CO}_{2}$ emissions. The share of shipping emissions in global anthropogenic emissions has increased from $2.76 \%$ in 2012 to $2.89 \%$ in 2018 [2].

The values for global $\mathrm{CO}_{2}$ emissions and the share that falls for the shipping industry in the period of $2012 \div 2018$ are given in Table 1 (units are in million tonnes).

\footnotetext{
*Corresponding author: v.nikiforov@tu-varna.bg
} 
Table 1. Total Global and Shipping $\mathrm{CO}_{2}$ Emissions (Source - IMO GHG Study 2020)

\begin{tabular}{|c|c|c|c|}
\hline Year & Global CO Emissions & $\begin{array}{c}\text { Shipping CO} \mathbf{C O}_{2} \\
\text { Emissions }\end{array}$ & $\begin{array}{c}\text { Shipping as } \\
\text { percentage of global }\end{array}$ \\
\hline 2012 & 34793 & 962 & 2.76 \\
\hline 2013 & 34959 & 957 & 2.74 \\
\hline 2014 & 35225 & 964 & 2.74 \\
\hline 2015 & 35239 & 991 & 2.81 \\
\hline 2016 & 35380 & 1026 & 2.90 \\
\hline 2017 & 35810 & 1064 & 2.97 \\
\hline 2018 & 36573 & 1056 & 2.89 \\
\hline
\end{tabular}

Despite the shipping industry could be classified as the most environmentally friendly and economically profitable way to transport a large amount of goods the negative effect of the industry should also be considered. Annually the worldwide shipping uses a large amount of fossil fuels to operate the available fleet.

Even with the newly adopted requirements known as IMO 2020 which limits the sulphur content in the fuels used onboard of the ships to $0.50 \%$ outside Emission Control Areas (ECAs) and $0.10 \%$ inside ECAs, the ships equipped with devices for exhaust gas treatment are still able to use heavy fuel oils (HFO) with high sulfur content whose burning in the main engines lead to serious environmental pollution.

Of the around 56,000 merchant ships trading internationally, some 5400 are container ships, thus means that the container class accounts for about $10 \%$ of the global merchant fleet.

In Figure 1 is shown the number of the ships included in the global merchant fleet and the shares respectively for each ship's class engaged in the worldwide trading until 1st January 2020.

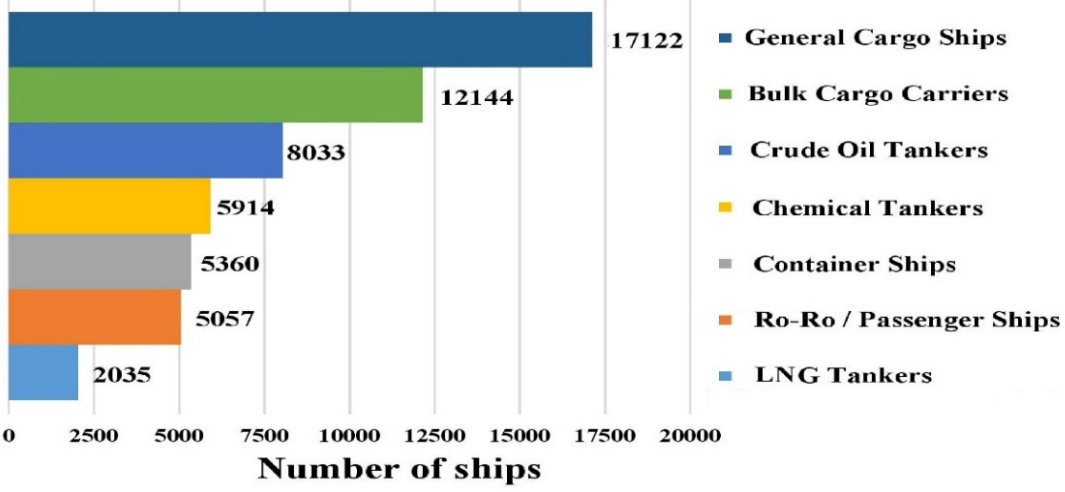

Fig. 1. Shares by ship's class involved in the global merchant fleet (Source - www.statista.com) 
Three ship classes accounted for $55 \%$ of the total shipping $\mathrm{CO}_{2}$ emissions: container ships $(23 \%)$, bulk carriers $(19 \%)$, and oil tankers (13\%), also these three ship classes accounted for $84 \%$ of total shipping transport supply (deadweight tonne nautical miles, or dwt-nm) [3]. In Figure 2 are depicted the $\mathrm{CO}_{2}$ emissions generation depending on the ship's class (Source $-[3])$.

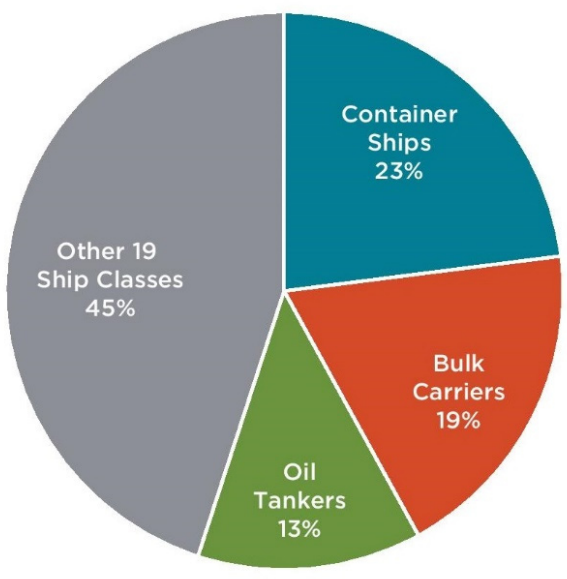

Fig. 2. Shares of $\mathrm{CO}_{2}$ emissions by ship's class

With purpose to achieve better Energy Efficiency and state of the environment improvement, the International Maritime Organization (IMO) and Marine Environment Protection Committee (MEPC) established some requirements in connection with reducing the GHG generated by the industry.

In 2011, IMO adopted mandatory technical and operational energy efficiency measures which are expected to significantly reduce the amount of $\mathrm{CO} 2$ emissions from international shipping. These mandatory measures (EEDI/SEEMP) entered into force on 1 January 2013. IMO has adopted important guidelines aimed at supporting implementation of the mandatory measures to increase energy efficiency and reduce GHG emissions from international shipping, paving the way for the regulations on EEDI and SEEMP to be smoothly implemented by Administrations and industry [4].

The EEDI represents a non-prescriptive, performance- based mechanism that leaves the choice of technologies to use in a specific ship design to the industry. As long as the required energy efficiency level is attained, ship designers and builders would be free to use the most cost-efficient solutions for the ship to comply with the regulations. EEDI is requiring a minimum energy efficiency level for new ships by stimulating continued technical development of all the components influencing the fuel efficiency of a ship and by separating the technical and design-based measures from the operational and commercial ones [5].

The ship's energy efficiency could be represented as a function of its main and auxiliary engines power and the work fulfilled (cargo transported for certain time). The required speed of the ship and the engines power can be reached by various types of propulsion systems.

In order to comply with the IMO requirements regarding the GHG generation, the ship engine manufacturers developed much more efficient engine types which are able to work either with gaseous or with conventional fuels. Increasingly wider applications are finding the so-called Dual-Fuel Engines, which are able to operate with gaseous fuels and a small portion of diesel as a pilot fuel. 
The energy efficiency of the ship could be improved and therefore the GHG emitting reduced by applying some of the various ways listed below:

- Pay more attention on the proper engine selection;

- Using fuels with lower carbon content;

- Speed reduction with purpose to decrease the Specific Fuel Oil Consumption (SFOC);

- Implementation of innovative and renewable technologies reducing the $\mathrm{CO}_{2}$ emissions.

If we consider the service speed of the ship and its deadweight as a constant value, we have to pay much more attention when choosing the propulsion system with purpose to select the proper one which leads to EEDI improvement and GHG reduction.

The aims set in the current paper is to describe a methodology for selecting the proper propulsion system type for small, medium and large container vessels based on calculations of various systems, comparing the energy efficiency achieved with each and choosing the most efficient one with regard to fulfill the IMO requirements intended to GHG Emissions.

In the current article will be observed three types of container vessels - Feeder, PostPanamax, and ULCV which could be classified respectively as small, medium and large ships. The distribution of the observed ships is approximately $55.2 \%$ of the total container ships by 2019 .

In Figure 3 is shown the distribution of the container vessels by their size (Source - [6]).

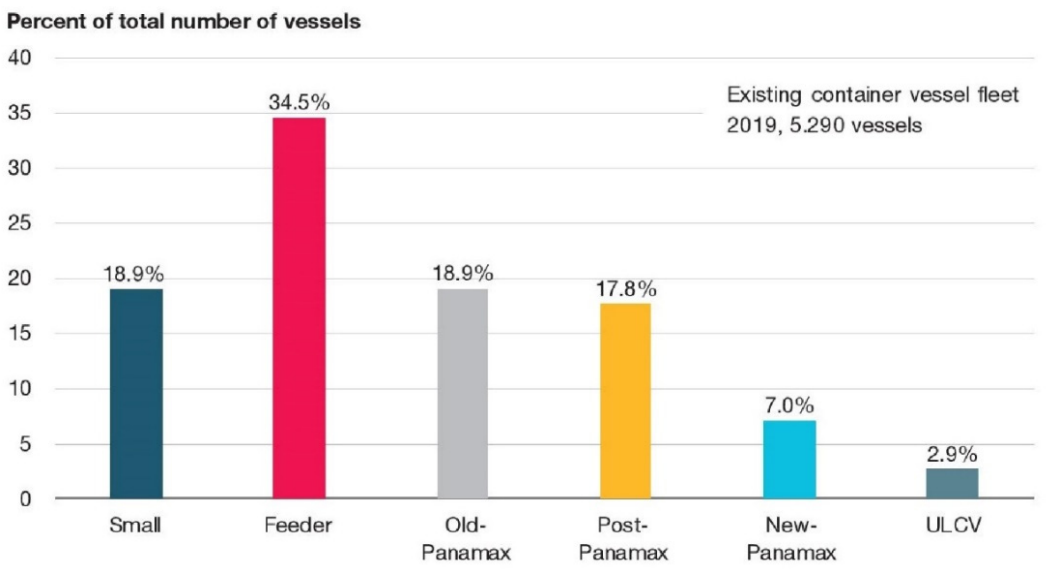

Fig. 3. Container vessels distribution by 2019

\section{Marine propulsion system types}

Nowadays there are a various options to configure a ship's propulsion system. The fuel oil consumption of the propulsion system mainly describing its cost efficiency is only the one side of the coin, but the other one is the ecology and the energy efficiency offering the use of each system type.

Today, ship propulsion is not just about successful movement of the ship in the water. It also includes using the best mode of propulsion to ensure a better safety standard for the marine ecosystem along with cost efficiency [7].

The common arrangement of the container ships propulsion system consists of a Main Engine (ME) and Diesel Generators (DG), but usually one ME and up to 3 DG are involved.

With the constantly tightening requirements regarding the ecology the ships have to comply with, the shipping industry have to adapt and implement new technologies. 
One of the methods to comply with the requirements is to run the fleet with engines using fuels with lower or none carbon content in comparison with the widely used conventional fuels like HFO and MDO.

The engines used in the ship's propulsion arrangement could be classified by various features, some of them listed below:

- By working cycle accomplishment - 2-stroke and 4-stroke engines;

- By their speed - Low-speed, Medium-speed and High-speed engines;

- By the fuel type used - Diesel or Dual-Fuel engines.

In the past decade, dual-fuel marine diesel engines using LNG as a secondary fuel, from either an LNG fuel tank or boil-off-gas, were developed and applied on board merchant vessels as an option to fulfil the IMO NOx Tier III regulations [8].

On Figure 4 is shown the typical arrangement commonly used in the container ship propulsion systems.

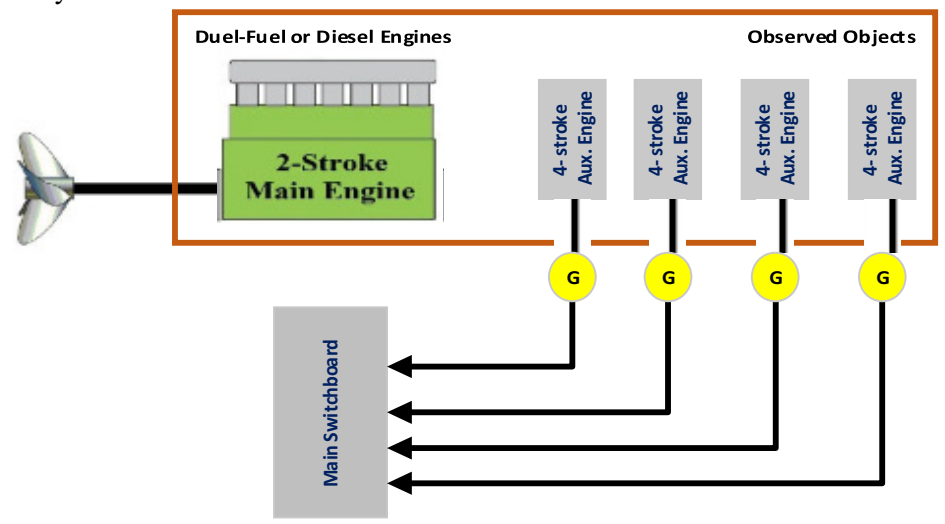

Fig. 4. Typical container ship propulsion system arrangement

In the current article will be considered various options for propulsion system arrangements for small, medium and large container vessels. This will be achieved by comparison of diverse propulsion systems using diesel or dual-fuel engines working on 2 or 4-stroke cycle. The comparison of the propulsion systems will be performed based on the achieved EEDI values depending on the fuel type used.

\section{Attained and Required EEDI calculation methodology}

The seaborne transport represents the most effective way of transport used nowadays, but the GHG and harmful emissions produced by the fossil fuels used in the internal combustion engines is a quite serious issue. Basically, the ship's energy efficiency is measured by the amounts of emissions radiated in the atmosphere and this effect could be accounted by calculating the ship's Attained EEDI and after that comparing it to the Required EEDI strictly depending on the ship's specific type and its capacity.

\section{Attained EEDI}

EEDI is mandatory for each new-built ship with gross tonnage equal to or above $400 \mathrm{GT}$ and could be considered as the most valuable indicator for her energy efficiency GHG emission level. EEDI is expressed in grams $\mathrm{CO}_{2}$ per tonne mile.

The methodology and requirements for Attained EEDI calculation for new ships are published by MEPC in [9]. 
The formula intended for Attained EEDI calculation of the ship includes CO2 emissions generated by the work done by the main and auxiliary engines, shaft motor and shaft generators and the reduction derived by the implementation of innovative energy efficient technologies. Thus, all is divided by the transport work done which could be represented as the multiplication of the ship's deadweight and her service speed.

The simplified formula for Attained EEDI calculation is listed below:

Where:

$$
\text { Attained } E E D I=\frac{\left(P_{M E(i)} \times C_{F M E(i)} \times S F C_{M E(i)}\right)+\left(P_{A E} \times C_{F A E} \times S F C_{A E}\right)}{f_{i} \times f_{c} \times f_{l} \times \text { Capacity } \times f_{w} \times V_{\text {ref }}}
$$

$\mathrm{P}_{\mathrm{ME}(\mathrm{i})}-75 \%$ of the rated installed power for each main engine (i);

$\mathrm{P}_{\mathrm{AE}}-$ is the required auxiliary engine power to supply normal maximum sea load including necessary power for propulsion machinery/systems and accommodation;

$\mathrm{C}_{\mathrm{FME}(\mathrm{i})}$ - conversion factor between fuel consumption and $\mathrm{CO}_{2}$ emissions for main engine(s); $\mathrm{C}_{\mathrm{FAE}(\mathrm{i})}$ - conversion factor between fuel consumption and $\mathrm{CO}_{2}$ emissions for auxiliary engine(s);

$\mathrm{SFC}_{\mathrm{ME}(\mathrm{i})}$ - specific fuel consumption of main engine at $75 \%$ of the rated power of the engine; $\mathrm{SFC}_{\mathrm{AE}}-$ specific fuel consumption of auxiliary engine at $50 \%$ of the rated power of the engine;

Capacity - for container vessels $70 \%$ of deadweight should be used as capacity;

$\mathrm{V}_{\text {ref }}$ - ship's speed at $75 \%$ power of the main engine;

$\mathrm{f}_{\mathrm{i}}$ - capacity factor;

$\mathrm{f}_{\mathrm{c}}$ - cubic capacity conversion factor;

$f_{l}$ - factor for general cargo ships equipped with cranes and other cargo related gear;

$\mathrm{f}_{\mathrm{w}}$ - weather factor.

If Power Take In / Power Take Off devices (PTI/PTO) and/or renewable energy efficiency technologies are used in composition of the ship propulsion system, their effect should also be accounted. This is achieved by supplementing the numerator of equation (1) with equation (2):

$$
\left(\left(f_{j} \times P_{P T I(i)}-f_{e f f(i)} \times P_{A E e f f(i)}\right) C_{F A E} \times S F C_{A E}\right)-\left(f_{e f f(i)} \times P_{e f f(i)} \times C_{F M E} \times S F C_{M E}\right)
$$

Where:

$\mathrm{f}_{\mathrm{j}}$ - correction factor for specific ship specific design elements;

$\mathrm{P}_{\mathrm{PTI}(\mathrm{i})}-75 \%$ of the rated power consumption of each shaft motor divided by the weighted average efficiency of the generator(s);

$f_{\text {eff(i) }}$ - the availability factor of each innovative energy efficiency technology;

$\mathrm{P}_{\text {AEeff(i) }}-$ is the auxiliary power reduction due to innovative electrical energy efficient technology;

$\mathrm{P}_{\text {eff(i) }}$ - the output of the innovative mechanical energy efficient technology for propulsion at $75 \%$ main engine power;

The required auxiliary engine power to supply normal maximum sea load including necessary power for propulsion machinery/systems and accommodations could be found by the following two principles:

For ships with a total propulsion power of $10000 \mathrm{~kW}$ or above, PAE have to be defined as follows:

$$
P_{A E}=\left(0.025 \times\left(M C R_{M E(i)}+\frac{P_{P T I(i)}}{0.75}\right)\right)+250
$$

For ships with a total propulsion power below $10000 \mathrm{~kW}, \mathrm{P}_{\mathrm{AE}}$ have to be defined as follows:

Where:

$\mathrm{MCR}_{\mathrm{ME}(\mathrm{i})}$ - maximum continuous rating of the main engine;

$$
P_{A E}=\left(0.05 \times\left(M C R_{(i)}+\frac{P_{P T I(i)}}{0.75}\right)\right)
$$


Generally, the full formula consisting of equations (1) and (2) could be simplified to much easier for understanding equation (5) as follows:

$$
E E D I=\frac{\mathrm{CO}_{2} \text { Emissions Generated }}{\text { Transport } \text { work }}
$$

More specific information regarding the calculation methodology, parameters and coefficients used for calculation of the EEDI for each ship could be found in [7].

\section{Required EEDI}

According to the requirements adopted by IMO and MEPC, each new-built ship EEDI value have to be in compliance with the reference value calculated for the corresponding ship type.

The REEDI is going to be decreased gradually and this is planned to be achieved in three phases as the last one has to be introduced in force from 1st January 2025 and aims for a reduction of REEDI by $30 \%$.

On Figure 5 are shown the reduction phases of REEDI thru the years [Source - [10])

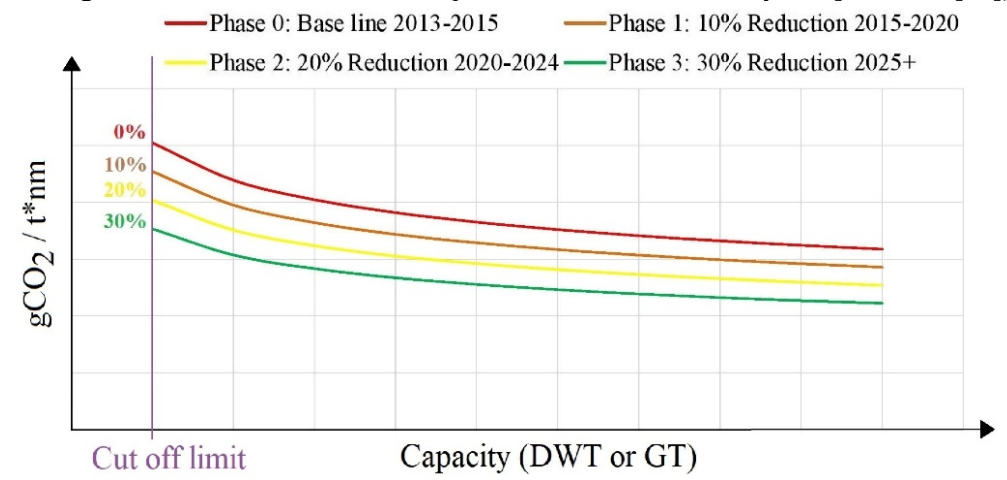

Fig. 5. REEDI reduction phases

The formula for calculating the REEDI is listed below:

$$
R E E D I=a \times b^{-c}
$$

In equation (6) the parameters " $a$ " and "c" are determined from the regression curve fit and they are specified in [9] and [10], the parameter " $b$ " expresses the deadweight of the ship.

\section{Calculations and study results}

With regard to fulfil the goals set in this paper and to perform the necessary calculations for the propulsion systems which we intend to observe, first we have to choose some real ships or projects. For the purpose of this paper, we have chosen real container vessels of MSC company, which is one of the biggest companies in this field. The initial data necessary for the purpose of the calculations and for the size of the ships are presented in Table 2. More detailed information regarding the chosen ships could be found in [14].

Table 2. Initial data for small, medium and large container vessels

\begin{tabular}{|c|c|}
\hline \multicolumn{2}{|c|}{ MSC AMY } \\
\hline ME & MAN B\&W, 6L70MC, $16980 \mathrm{~kW}$ at $108 \mathrm{rpm}$ \\
\hline DG & MAN B\&W, $4 \times 6 \mathrm{~L} 23 / 30 \mathrm{H}, 1050 \mathrm{~kW}$ each \\
\hline TEU & 1683 \\
\hline
\end{tabular}




\begin{tabular}{|c|c|}
\hline Deadweight & $22308 \mathrm{t}$ \\
\hline Speed & Max 20.5 knots \\
\hline \multicolumn{2}{|r|}{ MSC ATHENS } \\
\hline ME & MAN B\&W, 9SME-C $8.2,47430 \mathrm{~kW}$ at $78 \mathrm{rpm}$ \\
\hline DG & MAN B\&W, $2 \times 8 L 32 / 40-4000 \mathrm{~kW}$ each, $2 \times 9 \mathrm{~L} 32 / 40-4500 \mathrm{~kW}$ each \\
\hline TEU & 8827 \\
\hline Deadweight & $95380 \mathrm{t}$ \\
\hline Speed & Max 22.0 knots \\
\hline \multicolumn{2}{|r|}{ MSC HAMBURG } \\
\hline ME & MAN B\&W, 11S90ME-C9, $59780 \mathrm{~kW}$ at $82 \mathrm{rpm}$ \\
\hline DG & MAN B\&W, 4 x 9L32/40, $4500 \mathrm{~kW}$ each \\
\hline TEU & 16652 \\
\hline Deadweight & $184100 \mathrm{t}$ \\
\hline Speed & Max 23.0 knots \\
\hline
\end{tabular}

For the purpose of this paper, we substitute the main components of the propulsion system (ME and DG) of each considered ship with alternative modern engines with equivalent power working on the Dual-Fuel principle. The rest of the ship's parameters remain unchanged.

In Table 3 are shown the chosen alternative options for each observed ship.

Table 3. Alternative propulsion options for small, medium and large container vessels

\begin{tabular}{|c|c|}
\hline \multicolumn{2}{|r|}{ MSC AMY } \\
\hline ME & MAN B\&W, 7G60ME-C10.5-GI, $16980 \mathrm{~kW}$ at $98 \mathrm{rpm}$ \\
\hline DG & MAN B\&W, 4 x 8L23/30DF, $1000 \mathrm{~kW}$ each \\
\hline \multicolumn{2}{|r|}{ MSC ATHENS } \\
\hline ME & MAN B\&W, 9G90ME-C10.5-GI, $47430 \mathrm{~kW}$ at $78 \mathrm{rpm}$ \\
\hline DG & MAN B\&W, $2 \times 8 \mathrm{~L} 35 / 44 \mathrm{DF}+2 \times 9 \mathrm{~L} 35 / 44 \mathrm{DF}, 4080 \mathrm{~kW}+4590 \mathrm{~kW}$ each \\
\hline \multicolumn{2}{|r|}{ MSC HAMBURG } \\
\hline ME & MAN B\&W, 11G95ME-C10.5-GI, $59780 \mathrm{~kW}$ at $82 \mathrm{rpm}$ \\
\hline DG & MAN B\&W, 4 x 9L35/44DF, $4590 \mathrm{~kW}$ each \\
\hline
\end{tabular}

For both - initial and alternative propulsion systems identical calculations for determination of the Attained EEDI have been conducted.

The calculations are performed according to the requirements exposed in Section 2 of the current article. The information concerning the specific fuel oil consumption of the ME and DG is based on the relevant engines project guides and with the help of CEAS (Computerized Engine Application System) application provided for free use on the official website of the company MAN B\&W. 
The reference speed of the observed ships at the relevant engine load necessary for EEDI calculations is estimated based on the equation (8) listed below:

$$
P_{B}=c \times V^{i}
$$

Where:

$\mathrm{P}_{\mathrm{B}}-\mathrm{ME}$ Power, [kW];

c - constant;

V - Ship's speed, [knots];

$\mathrm{i}$ - exponent, depending on the ship's size. For first estimations widely used in the practice is the adoption of $i=3$.

In Table 4 are given the full input data necessary for the calculations performed in the current article for Attained and Required EEDI.

Table 4. Input data necessary for the calculations of EEDI and REEDI for the observed ships

\begin{tabular}{|c|c|c|c|}
\hline Ship & MSC AMY & $\begin{array}{c}\text { MSC } \\
\text { ATHENS }\end{array}$ & $\begin{array}{c}\text { MSC } \\
\text { HAMBUR } \\
\text { G }\end{array}$ \\
\hline ME Power at $75 \%$ load, $[\mathrm{kW}]$ & 12735 & 35572.5 & 44835 \\
\hline ME SFOC at $75 \%$ (initial), $[\mathrm{g} / \mathrm{kWh}]$ & 170.5 (HFO) & 159.5 (HFO) & $\begin{array}{l}159.1 \\
\text { (HFO) }\end{array}$ \\
\hline ME SFOC at $75 \%$ (alt.), [g/kWh] & $\begin{array}{l}128.2 \text { (LNG) } \\
3.34 \text { (MDO) }\end{array}$ & $\begin{array}{l}126.9 \text { (LNG) } \\
3.36(\mathrm{MDO})\end{array}$ & $\begin{array}{l}121.5 \text { (LNG) } \\
3.70 \text { (MDO) }\end{array}$ \\
\hline DG Power (Equation 3), [kW] & 568.38 & 1435.75 & 1744.5 \\
\hline DG SFOC at $50 \%$ (initial), $[\mathrm{g} / \mathrm{kWh}]$ & $\begin{array}{c}196.5 \\
(\mathrm{MDO})\end{array}$ & $\begin{array}{c}197.0 \\
(\mathrm{MDO})\end{array}$ & $\begin{array}{c}197.0 \\
(\mathrm{MDO})\end{array}$ \\
\hline DG SFOC at $50 \%$ (alt.), $[\mathrm{g} / \mathrm{kWh}]$ & $\begin{array}{l}206.1 \text { (LNG) } \\
3.60 \text { (MDO) }\end{array}$ & $\begin{array}{l}193.5(\mathrm{LNG}) \\
3.80 \text { (MDO) }\end{array}$ & $\begin{array}{l}\text { 193.5(LNG) } \\
\text { 3.80(MDO) }\end{array}$ \\
\hline $\mathrm{C}_{\mathrm{F}}(\mathrm{HFO})$ & \multicolumn{3}{|c|}{3.114} \\
\hline $\mathrm{C}_{\mathrm{F}}(\mathrm{MDO})$ & \multicolumn{3}{|c|}{3.206} \\
\hline $\mathrm{C}_{\mathrm{F}}(\mathrm{LNG})$ & \multicolumn{3}{|c|}{2.750} \\
\hline Deadweight, [tonnes] & 22308 & 95380 & 184100 \\
\hline Ref. Speed, [knots] & 18.63 & 19.99 & 20.9 \\
\hline Coeff. ,,a“ & \multicolumn{3}{|c|}{174.22} \\
\hline Coeff. „-c“" & \multicolumn{3}{|c|}{0.201} \\
\hline
\end{tabular}

In Tables 5 and 6 are shown the calculated data regarding the Required and Attained EEDI for each ship using respectively the initial and the alternative proposed propulsion options.

Table 5. REEDI and AEEDI for the observed ships equipped with the initial propulsion systems

\begin{tabular}{|l|c|c|c|}
\hline \multicolumn{1}{|c|}{ Ship } & $\begin{array}{c}\text { MSC } \\
\text { AMY }\end{array}$ & $\begin{array}{c}\text { MSC } \\
\text { ATHENS }\end{array}$ & $\begin{array}{c}\text { MSC } \\
\text { HAMBURG }\end{array}$ \\
\hline $\begin{array}{l}\text { Base REEDI } \\
(2013 \div 2015)\end{array}$ & 23.28 & 17.39 & 15.23 \\
\hline $\begin{array}{l}\text { Phase 1 } \\
(2015 \div 2020)\end{array}$ & 20.96 & 15.65 & 13.71 \\
\hline
\end{tabular}




\begin{tabular}{|l|c|c|c|}
\hline $\begin{array}{l}\text { Phase 2 } \\
(2020 \div 2024)\end{array}$ & 18.63 & 13.91 & 12.19 \\
\hline $\begin{array}{l}\text { Phase 3 } \\
(2025+)\end{array}$ & 16.30 & 12.17 & 10.66 \\
\hline $\begin{array}{l}\text { Attained } \\
\text { EEDI }\end{array}$ & 24.7 & 13.94 & 8.65 \\
\hline
\end{tabular}

Table 6. REEDI and AEEDI for the observed ships equipped with the alternative propulsion systems

\begin{tabular}{|c|c|c|c|}
\hline Ship & $\begin{array}{c}\text { MSC } \\
\text { AMY }\end{array}$ & $\begin{array}{c}\text { MSC } \\
\text { ATHENS }\end{array}$ & $\begin{array}{c}\text { MSC } \\
\text { HAMBURG }\end{array}$ \\
\hline $\begin{array}{c}\text { Base REEDI } \\
(2013 \div 2015)\end{array}$ & 23.28 & 17.39 & 15.23 \\
\hline $\begin{array}{c}\text { Phase 1 } \\
(2015 \div 2020)\end{array}$ & 20.96 & 15.65 & 13.71 \\
\hline $\begin{array}{c}\text { Phase 2 } \\
(2020 \div 2024)\end{array}$ & 18.63 & 13.91 & 12.19 \\
\hline $\begin{array}{c}\text { Phase 3 } \\
(2025+)\end{array}$ & 16.30 & 12.17 & 10.66 \\
\hline $\begin{array}{c}\text { Attained } \\
\text { EEDI }\end{array}$ & 17.24 & 10.18 & 6.11 \\
\hline
\end{tabular}

Note:

- Green color - In compliance;

- Red color - Non-compliance.

In Figure 6 is shown the reduction in percentages between the Attained EEDI for initial and alternative propulsion systems.

Depending on the reduction percentages could be done a basic estimation of the positive effect rendered only by the propulsion system type.

\section{EEDI Reduction}

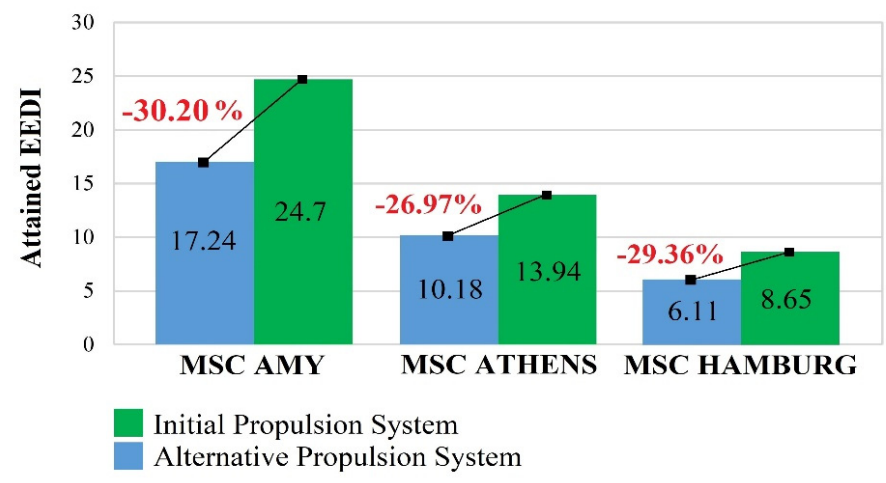

Fig. 6. EEDI reduction in percentages due to alternative propulsion system use

On Figures 7, 8 and 9 are graphically illustrated the calculated values for Attained EEDI regarding the observed in the current article ships respectively for the initial equipped and alternative propulsion systems proposed. 

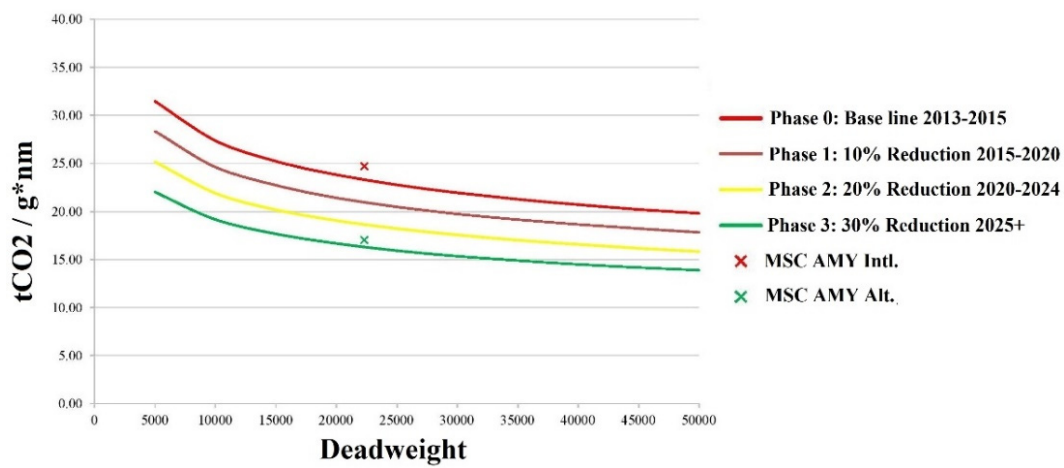

Fig. 7. Attained EEDI for small container vessel

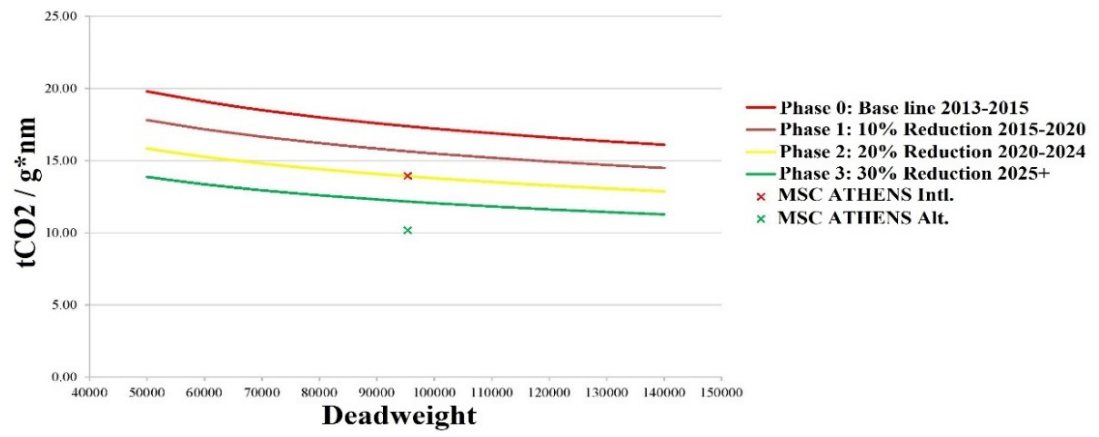

Fig. 8. Attained EEDI for medium container vessel

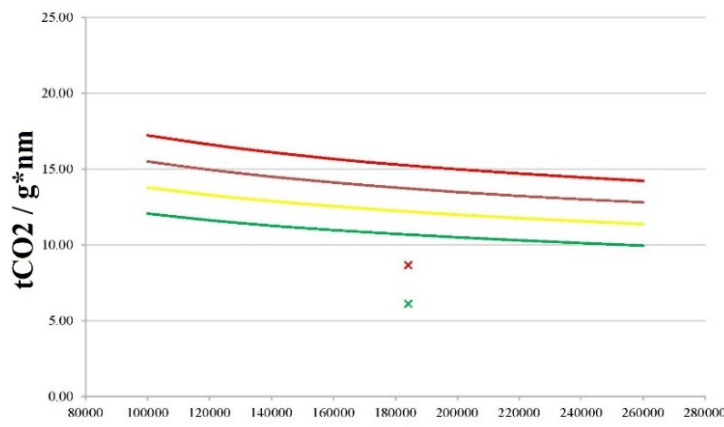

- Phase 0: Base line 2013-2015

- Phase 1: 10\% Reduction 2015-2020

Phase 2: 20\% Reduction 2020-2024

- Phase 3: 30\% Reduction 2025+

$\times$ MSC HAMBURG Intl.

$\times$ MSC HAMBURG Alt.

\section{Deadweight}

Fig. 9. Attained EEDI for large container vessel 


\section{Conclusions}

In the current paper had been observed three types of container vessels depending on their size - small, medium and large respectively. For the analyzed ships have been considered their initial equipped propulsion systems and then alternative modern options for the propulsion working on the Dual-Fuel principle have been proposed.

Based on the calculations performed in Section 3 of the present paper, first for the initial propulsion systems and then for the alternative options a significant improvement of the Attained EEDI has been found for each ship.

The improvement of the EEDI amounts to $30.20 \%$ for small, $26.97 \%$ for medium and $29.36 \%$ for large container vessels respectively. Average EEDI enhancement of $28.84 \%$ has been accounted for the three types of vessels observed.

Thanks to the switching to modern propulsion systems working on Dual-Fuel principle the observed ships are able to fulfil the stricter energy efficiency requirements introduced by IMO.

This work was performed within Project NP8/2021 from the Research Plan of the Technical University of Varna, financed by the State Budget. The first author has been funded in the frame of the Bulgarian National Science Program "Young Scientists and Postdoctoral Students 2021" (Council of Ministers' Decisions No. 577 / 16.08.2018).

\section{References}

1. https://www.statista.com/topics/1367/container-shipping/ (visited November, 2021)

2. Fourth IMO GHG Study 2020, Executive Summary - IMO

3. N. Olmer, B. Comer, B. Roy, X. Mao, D. Rutherford, Greenhouse gas emissions from global shipping, 2013-2015 (International Council on Clean Transportation 2017)

4. https://www.imo.org/en/OurWork/Environment/Pages/AirPollution-Default.aspx, (visited November, 2021)

5. Edmund Hughes (IMO), New Chapter for MARPOL Annex VI - requirements for technical and operational measures to improve the energy efficiency of international shipping (2013)

6. MAN Energy, Solutions Propulsion Trends in Container Vessels (2019)

7. www.marineinsight.com, Different Types of Marine Propulsion Systems Used in the Shipping World (2021)

8. H. Xing, St. Spence, H. Chen, A Comprehensive Review on Countermeasures for CO2 Emissions from Ships (2019)

9. Resolution mepc.245(66), 2014 Guidelines on the method of calculation of the attained energy efficiency design index (eedi) for new ships

10. IMO, Train the Trainer (TTT) Course on Energy Efficient Ship Operation, Module 2 Ship Energy Efficiency Regulations and Related Guidelines

11. Resolution mepc.203(62), Amendments to the annex of the protocol of 1997 to amend the international convention for the prevention of pollution from ships, 1973, as modified by the protocol of 1978 relating thereto

12. Resolution mepc.251(66), amendments to the annex of the protocol of 1997 to amend the international convention for the prevention of pollution from ships, 1973, as modified by the protocol of 1978 relating thereto

13. Resolution mepc. 231(65), 2013 guidelines for calculation of reference lines for use with the energy efficiency design index (eedi)

14. https://www.scheepvaartwest.be/CMS/index.php/containerships (visited November, 2021) 